\title{
Development of a Methodology for Evaluating the Impact of Technological Parameters of Hot Forging on Quality and Cost
}

\author{
${ }^{\square}$ Ainur Minnegayanovich Valiev, ${ }^{2}$ Dmitry Leonidovich Pankratov, ${ }^{3}$ Liliya Minnurovna Nizamova, ${ }^{4}$ Ravil \\ Salimovic Nizamov \\ 1,2,3,4 Department of Mechanical Engineering, Naberezhnye Chelny Institute of the KFU \\ AjMValiev@kpfu.ru \\ dlpankratov@kpfu.ru \\ nizamovalm@yandex.ru \\ nizamovrs@yandex.ru
}

Received: 21st August 2020, Accepted: 14th September 2020, Published: 31st October 2020

\begin{abstract}
The current trend in the development of mechanical engineering around the world in the development, mastering and implementation of new technologies that improve the quality of products, reduce the labour intensity, material consumption and production costs. A rational choice of workpieces for the manufacture of parts is a fundamental criterion that determines the cost of a part, its quality, production time and service life. However, a variety of methods for manufacturing workpieces creates significant difficulties in their rational choice. The variety of requirements (sometimes contradictory) for the workpieces further complicates the task of their rational selection. Shaft parts are the most common in mechanical engineering. Manufacturing of forgings for them is possible by the method of classical flash forging or by the method of cross-wedge rolling. Moreover, both methods have their advantages and disadvantages, so that the decisive factor in choosing a technology may well be the cost of forging. However, the technologist does not have a useful tool for a preliminary comparison of the influence of technological parameters on the final price. This estimate is usually limited to comparing material consumption (material consumption rate) and labour intensity (performance). With the expansion of the model range of manufacturing enterprises, the part range significantly increases, and the range of hot forgings is growing accordingly. The terms of technological manufacturing preparation for such positions are relatively tight. Design for manufacturability and launch of manufacture is mainly carried out on the basis of experience in illogical products. It should be noted that technologists have no time to think about the price-quality ratio and the use of alternative technologies. In addition, due to the increasing requirements for quality and reduction of production costs, the number of changes in the range of serially produced parts is growing. Often, savings in one cost item entail an increase in overall production costs or deterioration in the quality of products. Thus, a technologist, when working on a new order, shall understand how the use of an alternative technology or a change in an existing technological process will affect the cost price. This article is devoted to the establishment of the technological process parameters that have the most significant impact on the cost and quality of forgings. That is, it should be possible to maintain a "cost - quality" balance when working out a new order or changing a serial technology.
\end{abstract}

Keywords

Technological Parameters; Hot Die Forging; Production Cost; Quality; Forging.

\section{Introduction}

The chief way of ensuring the competing benefits of forging product is to increase its quality and implement a resilient pricing strategy through managing the production price, which is immediately associated with the manufacturing costs, that is, with the technological procedure of production forgings. This is dictated by the latest standard of IATF and the expansion policy of the world's foremost automobile manufacturers.

We have the following problem at present: there is no useful tool for assessing the impact of hot forging technological parameters on the expense and ensuring the forgings' quality at the stage of a preliminary study of forging manufacturing options with various types of hot forging [1;7-10]. As a result, it is difficult to maintain the "target price - acceptable quality" balance when developing a new order or changing a serial technology.

The primary purpose of the study was to develop a technological process parameters that hold a remarkable effect on the expense and quality of forgings. Also, it has been attempted to keep a "cost - quality" balance when working out a new order or changing a serial technology. 


\section{Methods}

This study is aimed at establishing the technological process parameters that own the most significant effect on the expense and forgings' quality. Regarding this sort of analysis, it is advisable to utilize a systematic method, while forging is regarded as a human-machine operation. The system' central components (Table. 1) are as follows: M processed material; P - measured workpiece (semi-finished product) taken from the processed material; E - equipment, which the forging is shaped on; TC - order and forms of technological influences on the workpiece back, through and later their forming; T - a device required for the technological process (TP) implementation; W - Wednesday; PP production personnel who design and implement the technical approach in a production environment.

Every part of the proposed matrix is designated by a multitude of factors affecting (to a particular degree) the achievement of the production task - the defect-free manufacture of forgings with a given performance and economic efficiency.

Table 1: Significance Matrix of the Impact of the Parameters of the System $\{P P, M, P, T C, E, T, W\}$ on the Production Expense and Forgings' Quality.

\begin{tabular}{|c|c|c|c|}
\hline \multirow{2}{*}{$\begin{array}{l}\text { System Elements } \\
\text { MBETTSE }\end{array}$} & \multicolumn{2}{|c|}{$\begin{array}{l}\text { Influence of } \\
\text { Parameters }\end{array}$} & \multirow{2}{*}{$\begin{array}{c}\text { Parameters that affect the Quality and } \\
\text { Cost of Forgings }\end{array}$} \\
\hline & $\begin{array}{c}\text { on } \\
\text { quality }\end{array}$ & on cost & \\
\hline \multicolumn{4}{|l|}{ Material } \\
\hline $\begin{array}{l}\text { The chemical combination of the } \\
\text { substance }\end{array}$ & $+\mathbf{\Delta} 5$ & $+\mathbf{\Delta} 5$ & - selectivity for each element \\
\hline \multirow{7}{*}{$\begin{array}{l}\text { Mechanical and physical } \\
\text { features of the material }\end{array}$} & $+\Delta \Delta 5$ & $+\mathbf{\Delta} 3$ & - macrostructure \\
\hline & $+\boldsymbol{\Delta} 5$ & $+\mathbf{\Delta} 3$ & - ultrasound \\
\hline & $+\mathbf{\Delta} 5$ & $+\mathbf{\Delta} 3$ & - non-metallic inclusions \\
\hline & $+\Delta \Delta 5$ & $+\mathbf{\Delta} 3$ & - magnetic properties \\
\hline & $+\mathbf{\Delta} 5$ & $+\mathbf{\Delta} 3$ & - landing in a hot and cold state \\
\hline & $+\mathbf{\Delta} 5$ & $+\mathbf{\Delta} 3$ & - carbon-free layer \\
\hline & $+\Delta 4$ & $+\mathbf{\Delta} 3$ & - skew cut of the workpiece \\
\hline \multicolumn{4}{|l|}{ Blank } \\
\hline Group of surface quality & $+\mathbf{\Delta} 5$ & $+\mathbf{\Delta} 5$ & - turning \\
\hline \multirow{2}{*}{$\begin{array}{l}\text { Dimensions of rolled metal } \\
\text { products }\end{array}$} & $+\mathbf{\Delta} 1$ & $+\mathbf{\Delta} 4$ & - measured and multiple lengths \\
\hline & $+\mathbf{\Delta} 4$ & $+\mathbf{\Delta} 4$ & - non-standard size profile \\
\hline \multirow{3}{*}{ Accuracy } & $+\mathbf{\Delta} 4$ & $+\mathbf{\Delta} 4$ & - accuracy group \\
\hline & $+\mathbf{\Delta} 4$ & $+\mathbf{\Delta} 4$ & - accuracy grade \\
\hline & $+\mathbf{\Delta} 4$ & $+\mathbf{\Delta} 4$ & - curvature \\
\hline Edge processing & $+\mathbf{\Delta} 1$ & $+\mathbf{\Delta} 2$ & - deburring at the ends \\
\hline Additional processing & $+\mathbf{\Delta} 4$ & $+\mathbf{\Delta} 2$ & - heat treatment \\
\hline The volume of original blank & $+\mathbf{\Delta} 4$ & $+\mathbf{\Delta} 5$ & - material costs \\
\hline Way of cutting & $+\mathbf{\Delta} 4$ & $+\mathbf{\Delta} 5$ & - metal consumption rate \\
\hline \multicolumn{4}{|l|}{ Equipment } \\
\hline Type of equipment & $+\mathbf{\Delta} 3$ & $+\mathbf{\Delta} 4$ & - energy consumption \\
\hline Productiveness & $+\boldsymbol{\Delta} 1$ & $+\circ 4$ & - machine time \\
\hline Maintenance & $+\mathbf{\Delta} 4$ & $+\bullet 2$ & - repair-complexity factor \\
\hline Load & $+\boldsymbol{\Delta} 1$ & $+\bullet 3$ & - load factor \\
\hline \multicolumn{4}{|l|}{ Technology } \\
\hline \multicolumn{4}{|c|}{ Heating } \\
\hline Type of heating & $+\boldsymbol{\Delta} 4$ & $+\mathbf{\Delta} 4$ & - energy carrier type \\
\hline Heating temperature & $+\boldsymbol{\Delta} \Delta 4$ & $+\boldsymbol{\Delta} \Delta \bullet 3$ & - consumption of power \\
\hline \multicolumn{4}{|c|}{ Shaping } \\
\hline \multirow{2}{*}{$\begin{array}{c}\text { Number of } \\
\text { technological transitions }\end{array}$} & $+\mathbf{\Delta} 4$ & $+\mathbf{\Delta} 5$ & - the time of formation \\
\hline & $+\mathbf{\Delta} 4$ & $+\mathbf{\Delta} 5$ & - power consumption \\
\hline Closed or open die forging & $+\mathbf{\Delta} 3$ & $+\mathbf{\Delta} 5$ & - the consumption of materials \\
\hline Lubrication (type) & $+\boldsymbol{\Delta} \Delta 4$ & $+\mathbf{\Delta} \Delta 3$ & $\begin{array}{l}\text {-the cost of lubrication } \\
\text { - lubricant consumption }\end{array}$ \\
\hline
\end{tabular}




\begin{tabular}{|c|c|c|c|}
\hline $\begin{array}{c}\text { Stamping overlays and } \\
\text { allowances }\end{array}$ & $+\boldsymbol{\Delta} 5$ & $+\mathbf{\Delta} 4$ & - consumption of basic material \\
\hline \multicolumn{4}{|l|}{ Tool } \\
\hline Persistence & $+\boldsymbol{\Delta} \bullet 4$ & $+\mathbf{\Delta} 4$ & $\begin{array}{l}\text { - the distribution of the cost of equipment } \\
\text { on the number of manufactured products }\end{array}$ \\
\hline \multirow{2}{*}{ Preheating } & \multirow{2}{*}{$+\boldsymbol{\Delta} \bullet 4$} & \multirow{2}{*}{$+\boldsymbol{\Delta} \Delta 4$} & - type of energy carrier \\
\hline & & & - power consumption \\
\hline \multicolumn{4}{|l|}{ Staff } \\
\hline Labor intensity & $+\mathbf{\Delta} 1$ & $+\mathbf{\Delta} 4$ & {$[10]$} \\
\hline Qualification & $+\mathbf{\Delta} \bullet 4$ & $+\mathbf{\Delta} \bullet 4$ & - category \\
\hline \multicolumn{4}{|l|}{ Environment } \\
\hline Working conditions & $+\mathbf{\Delta} 2$ & $+\boldsymbol{\Delta} \bullet 2$ & - provision of norms \\
\hline
\end{tabular}

The Pareto principle application, the essence of which is that $20 \%$ of efforts give $80 \%$ of the result, and the remaining $80 \%$ of efforts - only $20 \%$ of the result, identified six parameters that own the most significant effect on quality and expense.

1. Chemical composition of the material;

2. Group of surface quality of the original rolled metal;

3. Volume of the original workpiece;

4. Cutting method;

5. Forging overlaps and allowances.

6. Number of technological transitions;

\section{Results and Discussion}

1. Chemical composition. Each chemical element that is part of the steel affects its mechanical properties in its own way, that is, improves or worsens. Alloying elements are specifically introduced to change the mechanical and thermal properties.

Carbon (C), which is a required element and is usually found in steel in the form of a chemical compound Fe3C (iron carbide), with an increase in its content to $1.2 \%$, increases the hardness, strength and elasticity of steel and reduces its toughness and weldability.

Sulphur in steel improves machinability after forging. However, an increase in the sulphur content significantly reduces the mechanical properties of steel, in particular, its plasticity and corrosion resistance. Furthermore, high sulphur content leads to red brittleness during hot steel deformation.

The sulphur content in the range of $0.02-0.035 \%$ eliminates the premature failure of the cutting tool.

2. Group of surface quality is a feature that establishes the permissible surface defects of rolled steel products. There are three groups of surface quality of rolled metal. Depending on the quality group, there is a risk of surface or forged defects on the part.

For example, when forging of the shaft type using the HFCDP (hot forging crank is driven press), the entire workpiece surface is subject to plastic deformation. The top forging section is formed due to the metal collection from adjacent areas. That is, some types of hot forming (for example, cross-wedge rolling), the group of surface quality of the original metal rolling should be assigned taking into account the depth of surface defects and the minimum possible allowance for machining.

3. Volume of the original workpiece. In general, the volume of the actual workpiece includes the volume of forging and waste. Thus, the volume of the original workpiece may be decreased by reducing the volume of forging, that is, by reducing overlaps and allowances, or by reducing metal waste through the use of low-waste or closed forging.

To implement the technology of low-waste or closed forging, it is necessary to ensure the accuracy of the workpiece weight, its positioning along with the transitions. Hence there is the following requirement: rolled metal according to the first group of surface quality and cutting the workpieces by sawing. If the workpiece weight is reduced by $1 \%$, the cost of forging will be reduced by $0.9 \%$.

4. Cutting method. The deviation along the out-of-square workpiece sidewall for the case of cutting with saws is less than when cutting with press-shears, which provides better workpiece stability during the upsetting operation. This minimizes the risk of uneven metal distribution during the formation of transitions and the resulting difference in the forging height. In turn, this directly affects the accuracy of the forged product.

5. Forging overlaps and allowances. The allowance may be decreased due to the reduction of the maximum forging deviation values, such as tolerances for dimensions, for displacement along the surface of the die parting plane, for deviation from concentricity, for deviations in flatness and curvature, etc. according to GOST 7505. This is possible 
due to the tightening of technological parameters and the use of some technological methods, increasing the technical accuracy of the equipment itself, improvement of the accuracy of forging positioning along with the transitions, using the "lock" forging technology, etc.

That is, a significant reduction of forging allowances is possible by modernizing equipment, using modern methods to improve technological accuracy, including research and development.

Decreasing the allowances, without confirming the reduction of the allowable forging deviations, will lead to defects in the finished part after machining.

An unreasonable reduction in overlaps can lead to the formation of defects during forging (clamping, underfilling). 6. Number of technological transitions. An increase in the number of transitions makes it possible to increase the service life of the forging tool by 1.5-2 times and to reduce technological overlaps in some cases.

Comparison of the calculated values of the tool engraving wear based on the simulation results using the example of forging in two and three transitions at $900{ }^{\circ} \mathrm{C}$ are presented in Table 2 .

Table 2: Forging Tool Wear for 2 and 3 Punching Transitions.

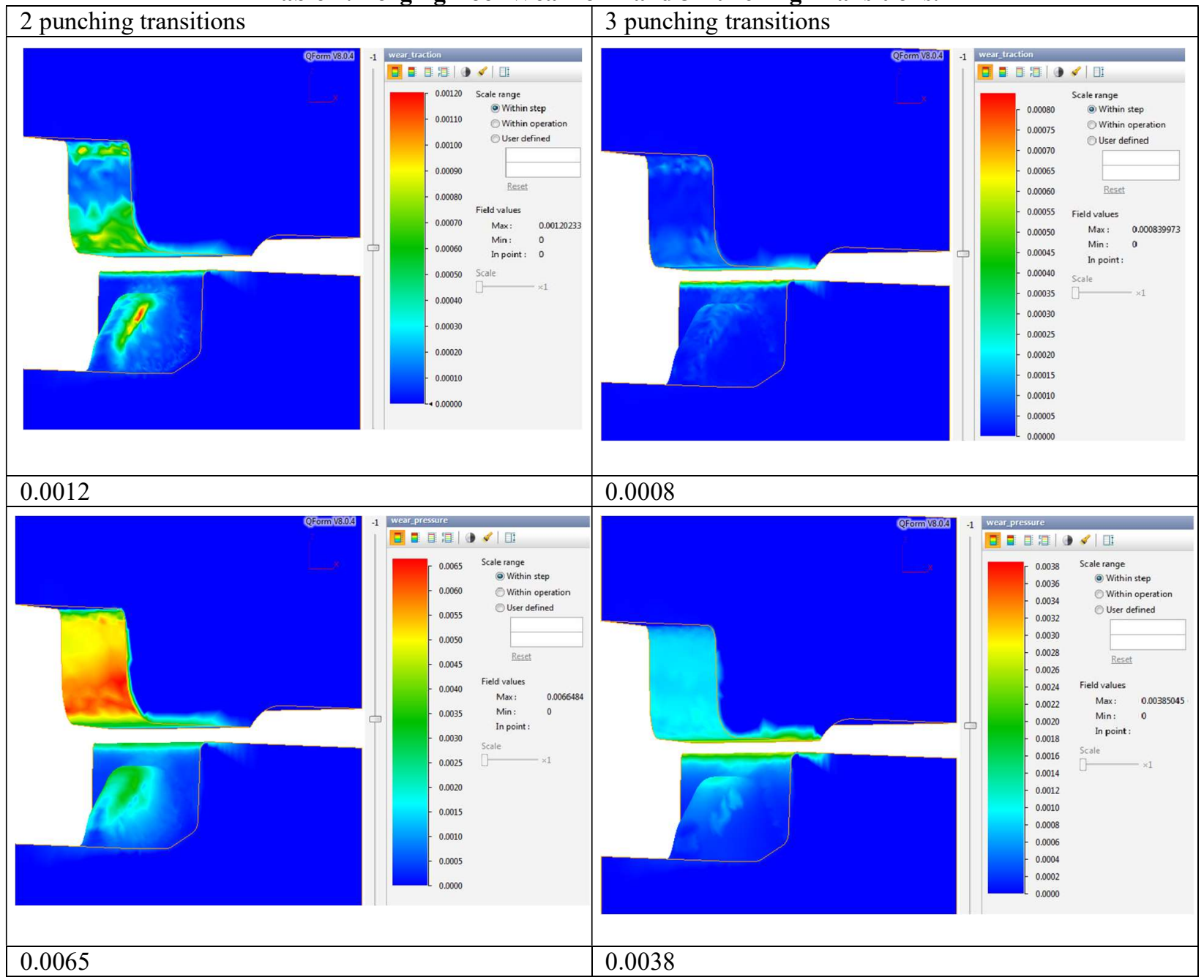

The study shows the area with the most intensive die wear. That is the specified part of the engraving will be damaged in the first place. The use of the final three transitions reduces the maximum wear values by $1.5 \div 1.7$ times. Depending on the requirements for the product quality, production volumes and capabilities of the separately considered production (restrictions), it shall be selected a specific scheme of the technological hot forging process.

The result of the work done is a method for determining the technological parameters of hot forging, ensuring the production of forgings within the limits of permissible deviations, keeping the "cost - acceptable quality" balance. For the general case, when designing a hot die forging process, the established technological parameters affecting the cost and quality should be assessed at the following stages (Fig. 1). 


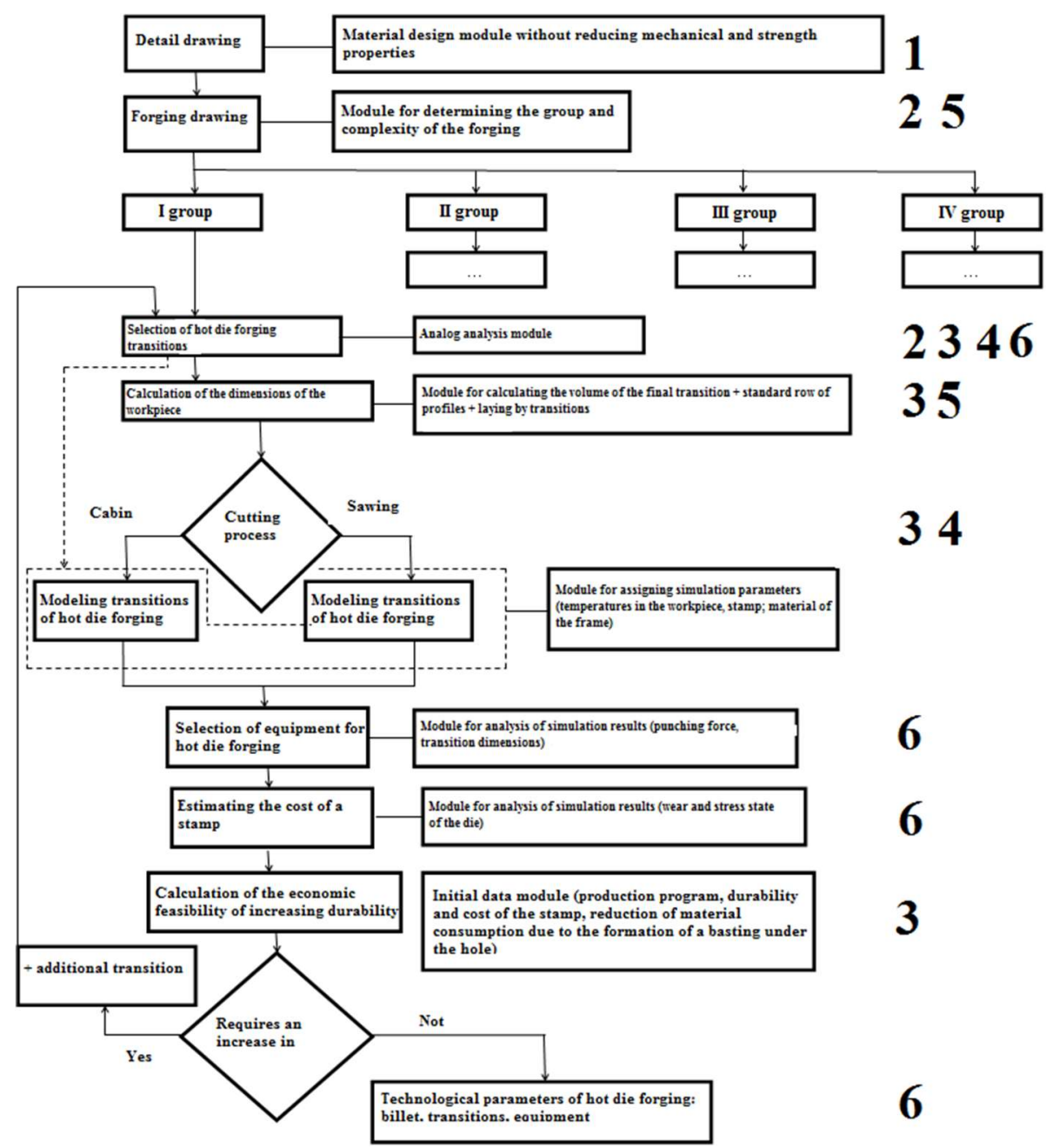

Fig. 1: Stages of Parameter Estimation.

For the general case of estimating the cost at the stages of the hot forging technology development, use the data in Table 3 .

Table 3: Influence of Hot Forging Parameters on the Production Cost.

\begin{tabular}{|c|c|c|c|c|}
\hline No. & $\begin{array}{c}\text { Name of } \\
\text { parameter }\end{array}$ & Coefficient & Value of coefficient & Note \\
\hline 1 & $\begin{array}{l}\text { The chemical } \\
\text { composition of } \\
\text { the material }\end{array}$ & $\mathrm{K}_{1}$ & $\approx 1,05$ & Surcharge for selectivity \\
\hline 2 & $\begin{array}{l}\text { Surface quality } \\
\text { group (QG) }\end{array}$ & $\mathrm{K}_{2}$ & $\begin{array}{c}1 \mathrm{QG} \approx 1,15 \\
2 \mathrm{QG} \approx 1,1 \\
3 \mathrm{QG} \approx 1\end{array}$ & $\begin{array}{l}\text { Surcharge for surface quality } \\
\text { group }\end{array}$ \\
\hline 3 & $\begin{array}{l}\text { The volume of } \\
\text { original blank }\end{array}$ & $\mathrm{K}_{3}$ & Decreased by $1 \%$ & $\begin{array}{l}\text { For closed or low waste } \\
\text { stamping. } \\
\text { P.S. For closed stamping } \times \\
1,15(1 \text { QG }) \times 0,85 \times(\text { sawing })\end{array}$ \\
\hline 4 & Way of cutting & $\mathrm{K}_{4}$ & 1,022 & $\begin{array}{c}\text { Improving the accuracy of the } \\
\text { workpiece volume }\end{array}$ \\
\hline 5 & $\begin{array}{c}\text { Allowances and } \\
\text { overflows }\end{array}$ & $\mathrm{K}_{5}$ & $\approx 0,97$ & Improving punching accuracy \\
\hline 6 & $\begin{array}{l}\text { Stamping } \\
\text { transitions }\end{array}$ & $\mathrm{K}_{6}$ & $\approx 0,97$ & $\begin{array}{c}\text { Increased accuracy, reduced } \\
\text { overlaps }\end{array}$ \\
\hline
\end{tabular}


Let us consider an example of the application of the methodology for assessing technological parameters in the design of the intermediate shaft forging technology:

1. The customer selected the steel grade 18HGR. Suggest assigning carbon and sulphur selections to improve strength properties and part machinability. At the same time, the cost growth will be $2 \%$.

2. When making the forging drawing, the use of an alternative group of surface quality should be evaluated in order to reduce costs. However, it should be noted that when using 2 or 3 groups of surface quality, an increase in allowance and overlap for machining is very likely. This forging can be made in two ways: by forging using the HFCDP (hot forging crank is driven press) or CWR (cross-wedge rolling). Depending on the method, the number of allowances and overlaps, as well as the requirements for the original metal will differ. For example, when switching to $2 \mathrm{QG}$ rolled metal products and increasing the allowance by $6 \%$, the prime cost will decrease by approximately $8 \%$.

3. When forging using the HFCDP, 2 group of surface quality is sufficient. The original workpiece volume may be reduced by pre-profiling the workpiece by rolling. The cutting method will not affect the hot forming process in any way: neither when forging using the HFCDP, not CWR. Metal waste with HFCDP is higher than with CWR.

4. During forging, the volume of the original workpiece and allowance is greater than during rolling, because there is more metal waste in a flash. And an additional allowance is assigned, taking into account the permissible shift and increased tolerances.

5. The cutting method can be neglected when evaluating the technology of obtaining a forging shaft because the increased accuracy of the workpiece mass will not affect the flat punching and rolling of the cutting angle.

6. The cost of tooling is higher for CWR than for HFCDP. However, due to the absence of backing up of the waste transformations, the wedge tool life is higher.

However, the production transfer of the intermediate shaft forging from HFCDP to transverse wedge rolling will make it possible to implement the following improvements:

- increasing the accuracy of forgings;

- increasing the metal utilization rate due to a decrease in forging slopes, allowances, overlaps and tolerances in comparison with forgings obtained using the HFCDP;

- improving working conditions due to a decrease in noise effects due to the absence of shock effects;

- increasing productivity (1.2-1.5 times, compared to the HFCDP).

Table 4: Cost Comparison

\begin{tabular}{|c|c|c|c|}
\hline No. & Name of parameter & Crank press (CP) & Taper rolling (TR) \\
\hline 1 & $\begin{array}{c}\text { The chemical } \\
\text { composition of the } \\
\text { material }\end{array}$ & $\begin{array}{c}\text { select by } \mathrm{C} \text { and S } \\
+2 \%\end{array}$ & $\begin{array}{c}\text { select by } \mathrm{C} \text { and } \mathrm{S} \\
+2 \%\end{array}$ \\
\hline 2 & $\begin{array}{c}\text { Surface quality group } \\
\text { Cost of rolled metal (C) }\end{array}$ & $\begin{array}{c}\mathrm{CG} \\
\mathrm{V}_{\text {blank }} \times 0,8\end{array}$ \\
\hline 3 & $\begin{array}{c}\text { The volume of } \\
\text { original blank }\end{array}$ & $\mathrm{V}_{\text {blank }}$ & - \\
\hline 4 & Way of cutting & - & $\mathrm{V}_{\text {blank }} \mathrm{h} \times 0,97$ \\
\hline 5 & $\begin{array}{c}\text { Allowances and } \\
\text { overflows }\end{array}$ & $\mathrm{V}_{\text {blank }} \mathrm{h}$ & \\
\hline
\end{tabular}

Production cost for $\mathrm{HFCDP}=\mathrm{K}_{1} \times \mathrm{K}_{2} \times \mathrm{K}_{3} \times \mathrm{K}_{4} \times \mathrm{K}_{5} \times \mathrm{K}_{5}=1 \times 1 \times 1 \times 1 \times 1 \times 1=1$

Production cost for $\mathrm{CWR}=\mathrm{K}_{1} \times \mathrm{K}_{2} \times \mathrm{K}_{3} \times \mathrm{K}_{4} \times \mathrm{K}_{5} \times \mathrm{K}_{6}=1 \times 1,15 \times 0,8 \times 0,97 \times 0,97 \approx 0,87$

$\mathrm{K}_{\mathrm{CP}}=1>\mathrm{K}_{\mathrm{TR}} \approx 0,87$

In case of a mass order exceeding more than 100 thousand per year, the use of a wedge tool is more expedient than the use of a die for the HFCDP. When switching to a control panel, cost reduction will be $13 \%$ (Table 4).

\section{Summary}

In the course of the research, we established the parameters of the technological process, having the greatest impact on the cost and quality of forgings. We also determined the following recommendations:

1. The chemical composition should be assessed at the initial study of the customer's CTD. An increase in the forging cost due to the use of selectivity surcharges will be $2 \%$.

2. The purpose of the group of surface quality of the original rolled metal should be assessed at the design stages of the forging drawing and the selection of hot die forging transitions. If $1 \mathrm{QG}$ is used instead of $2 \mathrm{QG}$, the production cost of forging will increase by $11 \%$. 
3. The volume of the original workpiece should be estimated at the stages of determining the number of transitions, calculating the workpiece size, and selecting the workpiece cutting method. If the workpiece weight is reduced by $1 \%$, the cost of forging will be reduced by $0.9 \%$.

4. The cutting method should be evaluated during the design and transition stages.

5. Allowances and overlaps should be assessed at the design stages of the forging drawing and calculation of the workpiece size. For example, when switching to $2 \mathrm{QG}$ rolled metal products and increasing the allowance by $6 \%$, the prime cost will decrease by approximately $8 \%$.

6. Forging transitions should be evaluated at the determination of transitions, hot forging equipment, and die life assessment.

\section{Conclusions}

We evaluated the influence of the main technological parameters of hot forging on the production cost and quality of forgings. As a result, we developed a method for assessing the influence of technological parameters of hot die forging on cost and quality.

\section{Acknowledgements}

The work is performed according to the Russian Government Program of Competitive Growth of Kazan Federal University.

\section{References}

[1] Aksenov, L.B. (1990). System design of stamping processes. L.: Mechanical engineering, Leningrad Department, $-284 \mathrm{p}$.

[2] Kashapova, L.R., Pankratov, D.L., Shibakov, V.G., \& Vinogradov, A.I. (2016). Providing the quality of complexly shaped machine elements at the design phase of the sheet stamping technological process. Journal of machinery manufacture and reliability, 45(1), 72-77.

[3] Maksymenko, D.V., \& Golovachko, V.M. (2018). Analysis Of The Efficiency Of The Use Of Fixed Assets. 274276. 10.31339/2617-0833, 24(1), 274-276.

[4] Shibakov, V.G., Pankratov, D.L., \& Khairullin, R. (2017). Systems analysis of process control capabilities for forging accuracy. In Solid State Phenomena, 265: 1110-1115). Trans Tech Publications Ltd.

[5] Shibakov, V.G., Pankratov, D.L., Nizamov, R.S., Hairullin, R.A. (2018). Surface quality assurance of ring gear during precision stamping of gearwheels. In IOP Conf. Series: Materials Science and Engineering, 412, p. 012073.

[6] Tang, D., \& Gao, B. (2007). Feature-based metal stamping part and process design. Part I: stampability evaluation. International journal of production research, 45(12), 2673-2695.

[7] Teterin, G.P., \& Polukhin, P.I. (1979) Basics of optimization and automation of the design of technological processes for hot die forging. - M.: Mechanical Engineering, - 284 p.

[8] Zolotov, A.M. (2002). Basics of designing precision multi-pass hot plastic processing technology using computer-aided design. St. Petersburg: Publishing House of the St. Petersburg State Technological Institute, ISBN 57422-0264-4

[9] Zolotov, A.M., \& Rudskoy, A.I. (2001). Designing and predicting the quality of die forging processes based on mathematical modeling. Collection of Articles of the Jubilee Scientific and Technical Conference of the Academy of Engineering Sciences of the Russian Federation, Northwest Branch. - St. Petersburg: Publishing House of the St. Petersburg State Technological Institute

[10] Zolotov, A.M., \& Rybin, Y.uI. (1999). Integrated design system for multi-transition plastic deformation processes. Collection of Articles of the International Scientific and Technical Conference "High Technologies in Modern Materials Science". St. Petersburg. 